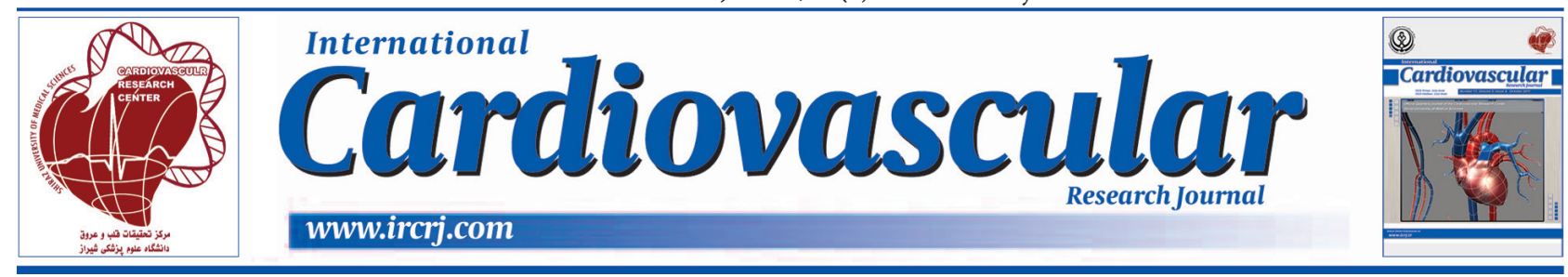

\title{
Examining the Health-Related Quality of Life after Coronary Artery Bypass Grafting and Percutaneous Coronary Intervention in Iran via SF-36 and SAQ
}

\author{
Nourolhoda Fakhrzad ${ }^{1}$, Reza Goudarzi ${ }^{2, *}$, Mohsen Barouni ${ }^{3}$, Javad Kojuri ${ }^{4}$, Yunes Jahani ${ }^{3,5}$ \\ ${ }^{1}$ Center of Excellence for Electronic Learning in Medical Sciences, Shiraz University of Medical Sciences, Shiraz, IR Iran \\ ${ }^{2}$ Health Services Management Research Center, Institute for Futures Studies in Health, Kerman University of Medical Sciences, Kerman, IR Iran \\ ${ }^{3}$ Modeling in Health Research Center, Institute for Futures Studies in Health, Kerman University of Medical Sciences, Kerman, Iran \\ ${ }^{4}$ Education Development Center, Shiraz University of Medical Sciences, Shiraz, IR Iran \\ ${ }_{5}^{5}$ Department of Biostatistics and Epidemiology, School of Public Health, Kerman University of Medical Sciences, Kerman, IR Iran
}

\begin{tabular}{l}
\hline A R T I C L E I N F O \\
\hline Article Type: \\
Research Article \\
\hline
\end{tabular}

Article History:

Received: 24 Jul 2015

Revised: 07 Nov 2015

Accepted: 15 Nov 2015

\section{Keywords:}

Quality of Life

Questionnaires

Coronary Artery Bypass

Percutaneous Coronary Intervention

\begin{abstract}
A B S T R A C T
Background: Cardiovascular Disease (CVD) is one of the major concerns all around the world. It is caused by mass of atherosclerotic plaques in the walls of coronary arteries, which ends in narrowing of veins, heart failure, angina, and Myocardial Infarction (MI). The growing need for therapeutic interventions in CVD patients illustrates the importance of paying special attention to these patients' Quality of Life (QoL) and the vital interventions for their treatment.

Objectives: This research aimed to evaluate patients' QoL after Coronary Artery Bypass Grafting (CABG) and Percutaneous Coronary Intervention (PCI) using Seattle Angina Questionnaire (SAQ) and Short Form-36 (SF-36).

Patients and Methods: This six-month cohort study aimed to evaluate the QoL among CAD patients in Shiraz, Iran via SAQ and SF-36. The study population included all the patients who had undergone CABG and PCI in the hospitals of Shiraz University of Medical Sciences from May to December 2014. A total of 200 patients were selected for each intervention. After gaining the patients' consent to take part in the research, 200 patients who applied for CABG and 198 patients who applied for PCI agreed to participate in the study. Preintervention data were gathered through a demographic data form and two valid and reliable questionnaires for QoL. The post-intervention data were also gathered six months after the treatment using the same questionnaires. Then, the data were entered in to the SPSS statistical software, version 20 and were analyzed using paired sample t-test, Kruskal-Wallis, Mann-Whitney U, ANOVA, and Spearman and Pearson correlation coefficient.

Results: Intervention was proved to be the most effective factor in changing the patients' $\mathrm{QoL}(\mathrm{P}=0.04$, mean $\pm \mathrm{SD}=4.65 \pm 22.02$ for $\mathrm{PCI}$ and $8.25 \pm 22.97$ for CABG using SF36; $\mathrm{P}=0.002$, mean $\pm \mathrm{SD}=10.54 \pm 17.14$ for $\mathrm{PCI}$ and $15.47 \pm 16.81$ for CABG using SAQ). Moreover, both intervention types boosted the patients' $\mathrm{QoL}(\mathrm{P}<0.001)$. However, CABG appeared to be more successful in boosting the QoL compared to PCI. Additionally, although CABG did notexert any significant effects on the score of physical limitation (P $=0.74$ ), it had impacts on all the features of SAQ.

Conclusions: The findings revealed that although both CABG and PCI boosted the QoL, CABG was more effective in changing this factor.
\end{abstract}

Implication for health policy/practice/research/medical education:

The growing need for therapeutic interventions in CVD patients points to the importance of paying special attention to these patients' quality of life and the necessary interventions for their treatment. Therefore, this research aimed at evaluation of Iranian patients' quality of life after CABG and PCI via SAQ and SF-36.

*Corresponding author: Reza Goudarzi, Health Services Management Research Center, Institute for Futures Studies in Health, Kerman University of Medical Sciences, Kerman, Iran, Tel: +98-3431325408; Fax: +98-3431205222, E-mail: rgoudarzi@kmu.ac.ir

\section{Background}

Today, every country is faced with health-threatening problems, some of which are known and others need to 
be further investigated. Cardiovascular Disease (CVD) is one of the major concerns all around the world (1). CVD is one of the three main leading causes of death in the world (2) and it has been predicted that 7 out of 10 death cases in the world will be due to chronic diseases related to CVD by 2030 (3-5). In Iran also, CVD has been claimed to be a major problem in social and health care, with the number of patients increasing every day. Accordingly, attention should be directed toward more important aspects, such as Quality of Life (QoL), since individuals not only want to live longer, but they also want to have improved QoL (6). QoL has been defined by World Health Organization (WHO) (1991) as individuals' understanding of their own cultural situation in life and the value system in which they live, including targets, standards, expectations, and preferences. Accordingly, QoL is a mental issue that cannot be seen by others and rides on individuals' perception of diverse aspects of life (7). Disorder in QoL escalates both indirect and direct effects. Indirect effects include negative effects on social life, family, job, and recreation, while direct effects include hospitalization and death as a result of the disease (8). CVD is caused by mass of atherosclerotic plaques in the walls of coronary arteries, leading to narrowing of veins, heart failure, angina, and Myocardial Infarction (MI) (2). Treatment of the patients with CVD follows two goals, namely preventing the expansion of the disease and increasing patients' tolerance to bear the illness (9). Overall, CVD can be treated through several methods, such as Coronary Artery Bypass Grafting (CABG) and Percutaneous Coronary Intervention (PCI) (10). Up to now, numerous studies have been conducted on evaluation of QoL in CVD patients. Some researchers (e.g., Cohen et al., 2011; Spertus et al., 1994) studied the effect of treatment procedures on the QoL in CVD patients by both Seattle Angina Questionnaire (SAQ) and Short Form-36 (SF-36) and compared these two instruments (9, 11). Additionally, some studies (e.g., Favarato et al., 2007; Rumsfeld et al., 2004; Tofighi et al., 2012; Vinceljet al., 2014) evaluated health-related QoL among patients with CVD through SF-36 (12-15). Other studies (e.g. Borkon et al., 2002; Moattari et al., 2014; Taherikhorame etal., 2014; Zhang et al., 2003) also examined the effect of angina and improvement of healthon QoL in patients with CAD using SAQ (16-19). Likewise, Stafford et al. (2009) conducted a study in Australia to scrutinize the relationship between heart disease beliefs and health-related QoL (20).

\section{Objectives}

The growing need for therapeutic interventions in CVD patients points to the importance ofpaying special attention to these patients' QoL and the necessary interventionsfor their treatment. Thus, this research aims to evaluate Iranianpatients' QoL after CABG and PCI via SAQ and SF-36.

\section{Patients and Methods}

This six-month cohort study aimed to evaluate the QoL among CAD patients in Iran through SAQ and SF-36. The research population included all the patients who had undergone CABG and PCI in the hospitals of Shiraz
University of Medical Science from May to December 2014. From beginning of the study, the samples were selected among the patients who were under treatment in the hospital. In this way, the researchers had no role in the patients' treatment process. Six months after CABG and/or PCI, the patients were debriefed via phone call. In effect, the patients were followed after six months of their treatment in the hospital. Using equation (1) and considering power of $80 \%$ and mean difference of 7,170 patients were selected for each treatment method. It is worth mentioning that considering statistical consistency and loss of some patients during the study, 215patients were selected for each group.

$$
n=\frac{\left(z_{1-\frac{\alpha}{2}}+z_{1-\beta}\right)^{2}\left(\sigma_{1}^{2}+\sigma_{2}^{2}\right)}{d^{2}}
$$

\section{Equation 1}

SD of QoL in the PCI group: $\sigma 1=23, \mathrm{SD}$ of QoL in the CABG group: $\sigma 2=22.8,1-\beta=0.80, \alpha=0.05, \mathrm{~d}=7$.

At first, the study objectives, voluntary participation, confidentiality of information, and freedom to discontinue participation at any time were explained to the patients and their written informed consents were obtained. Then, 215 patients who applied for CABG and 215 patients who applied for PCI were enrolled into the research. Pre-intervention data were gathered through SF-36 questionnaires, namely a general questionnaire for evaluating QoL and a specific questionnaire for evaluating the QoL inpatients with CAD; i.e., SAQ. It should also be noted that the data about the patients with diabetes and hypertension were obtained from their medical records. The post-intervention data were gathered six months after the treatment using the same questionnaires. After gathering the data, the questionnaires were scored and arranged according to a 0-100-point scale. Scoring was done before and after the intervention and the difference between the scores was computed.

The Persian version of SF-36 to evaluate health-related QoL contained 36 items in eight health dimensions, including physical function, role limitations due to physical health, bodily pain, general health, energy, social function, role limitations due to emotional problems, and emotional wellbeing. The items of each dimension were measured through either dichotomous options (yes or no) or six other options, namely always, usually, often, sometimes, rarely, and never. The measurement scores ranged from 0 to 100 representing the worst and the best conditions, respectively (18). This questionnaire was standardized and matched with the sociocultural situation in Iran. Various studies have employed this questionnaire as a valid instrument for heart disease (21). SF-36 was translated into Persian and has appropriate reliability and validity (22). SAQ was developed by Spertus et al. in 1995 (23). The original version of SAQ was used clinically to measure the basic dimensions of Coronary Artery Disease (CAD), including physical limitation, angina stability, angina frequency, treatment satisfaction, and disease perception (24). This five-dimensional and 19item questionnaire is too brief and the items are based on 5- or 6-point descriptive scales. This questionnaire was 
scored through assigning an ordinal value to each response, beginning with 1 for the lowest level of functioning. The items were then summed within each of the five or six subscales. After that, the scale scores were transformed into a range of 0 to $100(17,18)$. The validity of this questionnaire has been authenticated by Ravandet al (24). It should be mentioned that the questionnaires were completed blindly. After scoring the questionnaires, the data were entered into the SPSS statistical software, version 20 and were analyzed through descriptive (frequency, percentage, mean, and standard deviation) and inferential (paired sample t-test, Kruskal-Wallis, Mann-Whitney U, ANOVA, and Spearman and Pearson correlation coefficient) statistics.

\section{Results}

This study was conducted on 410 patients (210 CABG and 200 PCI). Overall, 5 patients in the CABG group and 15 ones in the PCI group were not interested in participation in the study. Demographic information of the 410 patients has been presented in Table 1. Accordingly, among the patients who had undergone $\mathrm{CABG}, 63.5 \%$ were male, 64\% were married, $57.5 \%$ used 'Iran Health Insurance', $39.5 \%$ had diabetes, and $34.5 \%$ suffered from hypertension. However, among the patients who had undergone PCI,
$62.6 \%$ were male, $87.9 \%$ were married, $62.6 \%$ used 'Iran Health Insurance', 15.2\% suffered from diabetes, and 25.3\% had hypertension. Besides, the patients' mean age was 58.65 \pm 11.19 years in the PCI group and $60.23 \pm 12.53$ years in the CABG group.

The relationship between changes in the QoL scores by SF36 and SAQ and demographic variables has been presented in Tables 2 and 3. Accordingly intervention was the only effective factor in change in the score of QoL $(\mathrm{P}=0.04$ in SF-36 and $\mathrm{P}=0.002$ in SAQ). The results also indicated that CABG was more powerful than PCI in boosting QoL. However, other variables had no significant effects on the change in the QoL score using SAQ and SF-36 (P > $0.05)$. Given that demographic variables had no significant effects on score change, they were not taken into account as confounders while comparing the two remedial methods.

The results of Wilcoxon test to compare the QoL before and after the intervention. According to the type of intervention have been shown in Table 4. As the table depicts, the change in the score of QoL was significant in both interventions using both instruments. Also, both intervention types increased the patients' QoL $(\mathrm{P}<0.05)$. Yet, change in the score of QoL was more in CABG compared to PCI. Additionally, score change was more in

\begin{tabular}{llll}
\hline Table 1. The Patients' Characteristics & & \\
\hline & Variables & CABG, N (\%) & PCI, N (\%) \\
\hline \multirow{2}{*}{ Sex } & Female & $73(36.5)$ & $74(37.4)$ \\
& Male & $127(63.5)$ & $124(62.6)$ \\
& Married & $128(64)$ & $174(87.9)$ \\
Marital statues & Single & $21(10.5)$ & $14(7.1)$ \\
& Window & $51(25.5)$ & $10(5.1)$ \\
Insurance & Iran Health insurance & $115(57.5)$ & $124(62.6)$ \\
& Social security Insurance & $78(39)$ & $67(33.8)$ \\
Diabetes & Other & $7(3.5)$ & $7(3.5)$ \\
& Yes & $79(39.5)$ & $30(15.2)$ \\
Hypotension & No & $121(60.5)$ & $168(84.8)$ \\
& Yes & $69(34.5)$ & 5.559 \\
\end{tabular}

\begin{tabular}{|c|c|c|c|c|}
\hline & Variables & Mean \pm SD of Score Change ${ }^{a}$ & Median (IQR $\left.{ }^{\mathrm{b}}\right)$ & Statistical Test Result \\
\hline \multirow{2}{*}{ Intervention } & PCI & $4.65 \pm 22.02$ & $0.35(20.47)$ & \multirow{2}{*}{$Z^{c}=-2.02, P=0.04$} \\
\hline & CABG & $8.25 \pm 22.97$ & $3.22(20.42)$ & \\
\hline \multirow{2}{*}{ Sex } & Female & $8.43 \pm 23.9$ & $4.51(21.14)$ & \multirow{2}{*}{$Z=-1.45, P=0.14$} \\
\hline & Male & $5.3 \pm 21.68$ & $1.57(16.89)$ & \\
\hline \multirow{3}{*}{ Marital statues } & Married & $7.16 \pm 22.18$ & $3.42(20.12)$ & \multirow{3}{*}{$\mathrm{Chi}^{\mathrm{d}}=4.49, \mathrm{P}=0.106$} \\
\hline & Single & $1.06 \pm 24.83$ & $0.02(9.89)$ & \\
\hline & Window & $6.08 \pm 22.92$ & $0.38(18.83)$ & \\
\hline \multirow{3}{*}{ Insurance } & Iran Health Insurance & $6.02 \pm 23.1$ & $0.5(17.37)$ & \multirow{3}{*}{ Chi $2=1.85, \mathrm{P}=0.39$} \\
\hline & Social security Insurance & $7.28 \pm 21.12$ & $3.09(21.54)$ & \\
\hline & Other & $5.33 \pm 28.27$ & $7.1(26.53)$ & \\
\hline Age & - & - & - & $\mathrm{r}^{\mathrm{e}}=0.007, \mathrm{P}=0.88$ \\
\hline \multirow{2}{*}{ Hypertension } & No & $6.56 \pm 22.51$ & $1.8(18.36)$ & \multirow{2}{*}{$Z=-0.003, P=0.99$} \\
\hline & Yes & $6.22 \pm 22.73$ & $2.63(21.42)$ & \\
\hline \multirow{2}{*}{ Diabetes } & No & $4.93 \pm 22.09$ & $1.8(19.85)$ & \multirow{2}{*}{$Z=-1.63, P=0.1$} \\
\hline & Yes & $10.5 \pm 23.32$ & $2.89(22.26)$ & \\
\hline
\end{tabular}

a Score change: the result of subtraction of the score of quality of life before the intervention from that after the intervention; ${ }^{\mathrm{b}} \mathrm{IQR}$, interquartile range; ${ }^{\mathrm{c}}$ Mann-Whitney U test; ${ }^{\mathrm{d}}$ Kruskal-Wallis test; ${ }^{\mathrm{e}}$ Spearman's correlation coefficient 


\begin{tabular}{|c|c|c|c|c|}
\hline & Variable & Mean \pm SD of Score Change & Median (IQR) & Statistical Test Result \\
\hline \multirow{2}{*}{ Intervention } & PCI & $10.54 \pm 17.14$ & $8.13(22.75)$ & \multirow{2}{*}{$\mathrm{Z}=-3.13, \mathrm{P}=0.002$} \\
\hline & CABG & $15.47 \pm 16.81$ & $14.87(22.76)$ & \\
\hline \multirow{2}{*}{ Sex } & Female & $13.01 \pm 18.73$ & $11.72(23.21)$ & \multirow{2}{*}{$\mathrm{T}=-0.001, \mathrm{P}=0.99$} \\
\hline & Male & $13.02 \pm 16.16$ & $13.19(21.39)$ & \\
\hline \multirow{3}{*}{ Marital statues } & Married & $13.61 \pm 17.18$ & $14.04(23.49)$ & \multirow{3}{*}{ Chi2 $=1.91, \mathrm{P}=0.38$} \\
\hline & Single & $10.43 \pm 16.34$ & $10.79(18.22)$ & \\
\hline & Window & $11.57 \pm 17.4$ & $9.55(23.57)$ & \\
\hline \multirow{3}{*}{ Insurance } & Iran Health Insurance & $12.69 \pm 17.09$ & $11.72(22.28)$ & \multirow{3}{*}{$\mathrm{F}^{\mathrm{a}}=0.72, \mathrm{P}=0.48$} \\
\hline & Social security Insurance & $13.98 \pm 17.09$ & $14.71(23.63)$ & \\
\hline & Other & $8.68 \pm 18.68$ & $9.54(27.43)$ & \\
\hline Age & - & - & - & $\mathrm{R}^{\mathrm{b}}=0.003, \mathrm{P}=0.94$ \\
\hline \multirow{2}{*}{ Hypertension } & No & $13.18 \pm 16.49$ & $13.66(22.59)$ & \multirow{2}{*}{$\mathrm{T}^{\mathrm{c}}=0.29, \mathrm{P}=0.77$} \\
\hline & Yes & $12.63 \pm 18.62$ & 10.15 & \\
\hline \multirow{2}{*}{ Diabetes } & No & $12.75 \pm 17.05$ & $12.04(22.97)$ & \multirow{2}{*}{$Z=-0.54, P=0.58$} \\
\hline & Yes & $13.71 \pm 17.41$ & $14.71(21.73)$ & \\
\hline
\end{tabular}

${ }^{\mathrm{a}}$ ANOVA; ${ }^{\mathrm{b}}$ t-test; ${ }^{\mathrm{c}}$ Pearson's correlation coefficient

\begin{tabular}{|c|c|c|c|c|c|c|}
\hline Intervention & CABG & & & PCI & & \\
\hline Instrument & Before & After & Statistical Test & Before & After & Statistical Test \\
\hline SAQ & $56.31 \pm 12.7$ & $71.78 \pm 13.08$ & $\mathrm{Z}^{\mathrm{a}}=-10.15, \mathrm{P}=0.00$ & $59.97 \pm 13.33$ & $70.51 \pm 14.64$ & $\mathrm{Z}^{\mathrm{a}}=-7.57, \mathrm{P}=0.00$ \\
\hline SF36 & $59.54 \pm 21.15$ & $67.8 \pm 18.65$ & $Z=-5.92, P=0.00$ & $59.18 \pm 20.51$ & $63.84 \pm 18.28$ & $Z=-319, P=0.001$ \\
\hline
\end{tabular}

${ }^{a}$ Wilcoxon test

SAQ in comparison to SF-36.

QoL based on the changes in the scores of SAQ and SF-36 dimensions and type of treatment before and after the intervention has been presented in Tables 5 and 6 . Accordingto Table 5, in SAQ, PCI had no significant effects on physical limitation $(\mathrm{P}=0.74)$, but there was a relationship between PCI and angina stability, angina frequency, treatment satisfaction, and disease perception. On the other hand, CABG affected all dimensions of SAQ.

According to Table6, in SF-36, PCI did not affect physical function ( $\mathrm{P}=0.38)$, emotional well-being $(\mathrm{P}=0.58)$, and social function $(\mathrm{P}=0.07)$. On the other hand, $\mathrm{CABG}$ affected all the dimensions, except for role limitations due to emotional problems $(P=0.6)$, energy/fatigue $(P=0.35)$, emotional well-being $(\mathrm{P}=0.31)$, social function $(\mathrm{P}=0.58)$, and pain $(\mathrm{P}=0.82)$.

\section{Discussion}

Nowadays, while comparing the effectiveness and relative value of different treatments, researches, and health policies, evaluation of health and treatment services, and improvement of the relationship between doctors and patients, QoL is considered to be a central issue. In other words, improvement of QoL is one of the goals of treatment in different fields of medicine. Previous studies showed that QoL was lower in CAD patients compared to the general population $(25,26)$. Therefore, the present research aimed to evaluate the QoL among CAD patients in Shiraz, Iran using SAQ and SF-36. The results demonstrated that intervention type, age, sex, marital status, insurance type, suffering from diabetes and hypertension, and type of intervention were the most effective factors in change of the QoL. This implies that there were no significant relationships between demographic variables and change in the score of QoL (Tables 1 and 2). This finding is consistent with that of the study by Tofighi et al., which indicated no significant relationships between changes in the score of QoL, and age and sex (14). However, it is in contrast to the results reported

\begin{tabular}{llllll}
\hline \multicolumn{6}{l}{ Table 5. Comparison of the Quality of Life According to Score Change in SAQ Dimensions before and after the Intervention } \\
\hline Intervention & Dimensions & Before (Mean) & After (Mean) & Mean Score Change \pm SD & Statistical Test \\
\hline \multirow{5}{*}{ PCI } & Physical limitation & 69.41 & 68.94 & $-0.47 \pm 19.23$ & $\mathrm{Z}=-0.33, \mathrm{P}=0.74$ \\
& Angina stability & 44.19 & 79.67 & $35.47 \pm 40.7$ & $\mathrm{Z}=-7.39, \mathrm{P}=0.00$ \\
& Angina frequency & 74.49 & 66.06 & $-8.43 \pm 33.52$ & $\mathrm{t}=3.96, \mathrm{P}=0.00$ \\
& Treatment satisfaction & 62.56 & 78.01 & $15.44 \pm 24.24$ & $\mathrm{~T}=-8.38, \mathrm{P}=0.00$ \\
& Disease perception & 49.20 & 59.89 & $10.69 \pm 25.78$ & $\mathrm{~T}=-5.28, \mathrm{P}=0.00$ \\
& Physical limitation & 67.96 & 72.74 & $4.77 \pm 17.79$ & $\mathrm{Z}=-3.02, \mathrm{P}=0.00$ \\
\multirow{5}{*}{ CABG } & Angina stability & 29.87 & 81.50 & $51.62 \pm 39.39$ & $\mathrm{~T}^{\mathrm{a}}=-17.81, \mathrm{P}=0.00$ \\
& Angina frequency & 74.00 & 64.15 & $-9.85 \pm 36.42$ & $\mathrm{~T}=4.6, \mathrm{P}=0.00$ \\
& Treatment satisfaction & 62.58 & 78.32 & $15.37 \pm 25.54$ & $\mathrm{~T}=-7.6, \mathrm{P}=0.00$ \\
& Disease perception & 47.12 & 62.20 & $15.08 \pm 25.02$ & $\mathrm{~T}=-7.39, \mathrm{P}=0.00$ \\
\hline
\end{tabular}

${ }^{a}$ paired sample t-test 


\begin{tabular}{|c|c|c|c|c|c|}
\hline Intervention & Scales & Before (Mean) & After (Mean) & Mean \pm SD of Score Change & Statistical Test \\
\hline \multirow{8}{*}{ PCI } & Physical functioning & 22.16 & 23.02 & $0.85 \pm 2.63$ & $\mathrm{Z}=-0.86, P=0.38$ \\
\hline & Role limitations due to physical health & 37.05 & 40.78 & $3.73 \pm 18$ & $\mathrm{~T}=-2.1, \mathrm{P}=0.03$ \\
\hline & role limitations due to emotional problems & 74.91 & 75.75 & $0.84 \pm 33.53$ & $\mathrm{Z}=-3.1, \mathrm{P}=0.002$ \\
\hline & Energy/fatigue & 69.13 & 78.97 & $9.84 \pm 37.73$ & $\mathrm{~T}=-3.29, \mathrm{P}=0.001$ \\
\hline & Emotional well-being & 73.24 & 82.57 & $9.33 \pm 33.64$ & $\mathrm{Z}=-0.55, \mathrm{P}=0.58$ \\
\hline & Social functioning & 73.35 & 80.80 & $7.44 \pm 33$ & $Z=-1.76, P=0.07$ \\
\hline & Bodily pain & 70.95 & 72.09 & $1.13 \pm 32.28$ & $\mathrm{Z}=-3.98, \mathrm{P}=0.00$ \\
\hline & General health & 52.65 & 56.72 & $4.06 \pm 0.03$ & $\mathrm{~T}=-2.15, \mathrm{P}=0.03$ \\
\hline \multirow{8}{*}{ CABG } & Physical functioning & 22.20 & 23.74 & $1.54 \pm 2.43$ & $\mathrm{Z}=-3.25, \mathrm{P}=0.001$ \\
\hline & Role limitations due to physical health & 34.15 & 46.02 & $11.86 \pm 20.97$ & $\mathrm{~T}=-6.65, \mathrm{P}=0.00$ \\
\hline & role limitations due to emotional problems & 70.1667 & 80.5 & $10.33 \pm 0.87$ & $\mathrm{Z}=-0.52, \mathrm{P}=0.6$ \\
\hline & Energy/fatigue & 76.44 & 84.06 & $7.61 \pm 35.7$ & $\mathrm{Z}=-0.91, \mathrm{P}=0.35$ \\
\hline & Emotional well-being & 78.40 & 86.15 & $7.74 \pm 33.32$ & $\mathrm{Z}=-1.01, \mathrm{P}=0.31$ \\
\hline & Social functioning & 75.52 & 82.63 & $7.11 \pm 32.5$ & $Z=-0.54, P=0.58$ \\
\hline & Bodily pain & 65.50 & 75.62 & $10.12 \pm 34.18$ & $\mathrm{Z}=-0.21, \mathrm{P}=0.82$ \\
\hline & General health & 53.98 & 63.66 & $9.67 \pm 17.92$ & $\mathrm{~T}=-6.05, \mathrm{P}=0.00$ \\
\hline
\end{tabular}

by Taheri, revealing a relationship between QoL, and sex and marital status (18). On the other hand, Tofighi et al. reported no significant relationships between the score of QoL and intervention type, which is on the contrary to the findings of the current research that indicated intervention type as the only effective factor in changing the CAD patients' QoL (14). The results of the present research disclosed that the patients' QoL was significantly different before and after the intervention via CABG and PCI, and significantly increased after the intervention. Vincelj et al. also reported an improvement in health-related QoL five years after CABG (15). Moreover, some studies (e.g., Rumsfeld, Moattari, Stafford, Borkon, Favarato, Zhang, and Cohen) disclosed that QoL was higher after CABG compared to $\mathrm{PCI}$, which is corresponding to the results of the current research $(11-13,16,17,19,20)$. This might be, to some extent, due to the need for repetition of PCI for angina within six months compared to CABG. Nevertheless, it should be considered that CABG is more offensive and, consequently, closer attention should be paid to its neural and psychological. Similarly, the findings of our study showed a significant relationship between PCI and 'angina stability', 'angina frequency', 'treatment satisfaction', and 'disease perception' in SAQ (Table 5). Spertus et al. also revealed a significant relationship between PCI and 'angina reliability', 'angina frequency', and 'disease perception' in SAQ. However, they reported that PCI had no significant impacts on 'treatment satisfaction' (9), which is in contrast to the results of the present study Lack of change in the patients' satisfaction level might be due to their satisfaction with the treatment through angioplasty. Our study findings also demonstrated significant relationships between CABG and all dimensions of SAQ (Table 5). As mentioned before, in SF-36, a significant relationship was found between PCI and role limitations due to physical health, role limitations due to emotional problems, energy/fatigue, pain, and general health. Also, a significant relationship was observed between $\mathrm{CABG}$ and physical function, role limitations due to physical health, and general health in SF-36 (Table 6). Similar results were also obtained by
Tofighi (14). Using SAQ in the present study, the highest and lowest scores of QoL in both interventions were related to 'angina stability' and 'disease perception', respectively (Table 5). In Zhang's study, however, the highest and lowest scores in both cases belonged to 'treatment satisfaction' and 'disease perception', respectively after six months (19). This implies that the patients' disease perception was lower compared to other dimensions of QoL. Using SF-36 also, the highest score of QoL in both interventions was related to emotional well-being. On the other hand, the lowest score was related to role limitations due to physical health in PCI and to physical functioning in CABG (Table 6). In Tofighi's study, the highest score of QoL belonged to role limitations due to emotional problems and the lowest score was related to general health (14). The difference between the results of the two studies might be attributed to the fact that in Tofighi's study, patients were examined during three years and, consequently, time turned up as an influential factor. One of the limitations of this research was using a limited number of effective variables in QoL in CVD patients. Therefore, other effective variables in QoL, such as smoking, diet, Body Mass Index (BMI), regular exercise, anxiety, and depression, are recommended to be investigated in future studies. To the best of our knowledge, no comparison has been made between the two specific and general questionnaires evaluating heart patients' QoL yet, which is another limitation of this study. Hence, further studies are suggested to compare the two questionnaires. Another limitation of this research was the time period of following up the patients' QoL after the intervention; i.e., six months after the intervention. Thus, a longitudinal study is recommended to be performed on QoL of the same group of patients. Nevertheless, the strong points of the current study included its large sample size as well as employment of random sampling method for selection of the participants, which increased the reliability of the results. Using both specific and general instruments for evaluating the QoL among the CVD patients was yet another advantage of this research. In conclusion, the findings of the present research disclosed that $\mathrm{CABG}$ led to more improvement 
in the QoL compared to PCI. Considering the fact that intervention is an effective factor in changing the QoL in patients undergoing CABG and PCI, it seems indispensable to pay more attention to the treatment method to improve the QoL in patients with CAD.

\section{Acknowledgements}

The authors would like to thank the personnel of the hospitals of Shiraz University of Medical Sciences for their cooperation.

\section{Authors' Contribution}

Study concept and design, acquisition of data, analysis and interpretation of data, drafting of the manuscript, critical revision of the manuscript for important intellectual content, statistical analysis, administrative, technical, and material support, and study supervision: Nourolhoda Fakhrzad, Reza Goudarzi, Mohsen Barouni, Javad Kojuri, Yunes Jahani.

\section{Financial disclosure}

The authors express that there are no financial interests related to the material in the manuscript.

\section{Funding/Support}

There is no financial and material support for this research.

\section{References}

1. Anand SS, Yusuf S. Stemming the global tsunami of cardiovascular disease. Lancet. 2011;377(9765):529-32.

2. Deaton C, Froelicher ES, Wu LH, Ho C, Shishani K, Jaarsma T. The global burden of cardiovascular disease. Eur J Cardiovasc Nurs. 2011;10 Suppl 2:S5-13.

3. Baird KK, Pierce LL. Adherence to cardiac therapy for men with coronary artery disease. Rehabil Nurs. 2001;26(6):233-7, 43.

4. Harrison T. Fauci, AS. Harrisons principle of internal medicine. New York: Mc Graw-Hill; 1998.

5. Paradis G, Chiolero A. The cardiovascular and chronic diseases epidemic in low- and middle-income countries: a global health challenge. J Am Coll Cardiol. 2011;57(17):1775-7.

6. Seyam S, Heidarnia AR. Quality of life and factors related to it in cardiovascular patients after heart surgery. Journal of Birjand University of Medical Sciences. 2013;19(6):33-41.

7. Hedayat DK, Karim H. Correlation between carotid stenosis and severity of coronary disease in diabetic candidates for angiography in cardiology clinic of Shariati Hospital in 2011. Journal of Kermanshah University of Medical Sciences (J Kermanshah Univ Med Sci). 2013;17(1):41-8.

8. Abedi H, YASAMAN AM, ABDEYAZDAN GH. Quality of life in heart failure patients referred to the Kerman outpatient centers, 2010. 2011.

9. Spertus JA, Winder JA, Dewhurst TA, Deyo RA, Fihn SD. Monitoring the quality of life in patients with coronary artery disease. Am J Cardiol. 1994;74(12):1240-4.

10. Huqi A, Morrone D, Capati E, Urselli R, Marzilli M. Prevalence of angina after successful PCI. Journal of the American College of Cardiology. 2010;55(10):A128. E1201.

11. Cohen DJ, Van Hout B, Serruys PW, Mohr FW, Macaya C, den
Heijer P, et al. Quality of life after PCI with drug-eluting stents or coronary-artery bypass surgery. N Engl J Med. 2011;364(11):1016-26.

12. Favarato ME, Hueb W, Boden WE, Lopes N, Nogueira CR, Takiuti $\mathrm{M}$, et al. Quality of life in patients with symptomatic multivessel coronary artery disease: a comparative post hoc analyses of medical, angioplasty or surgical strategies-MASS II trial. Int J Cardiol. 2007;116(3):364-70.

13. Rumsfeld JS, Ho PM, Magid DJ, McCarthy M, Jr., Shroyer AL, MaWhinney S, et al. Predictors of health-related quality of life after coronary artery bypass surgery. Ann Thorac Surg. 2004;77(5):1508-13.

14. Tofighi S, Ahmad Kiadaliri A, Sadeghifar J, Raadabadi M, Mamikhani J. Health-Related Quality of Life among Patients with Coronary Artery Disease: A Post-Treatment Follow-Up Study in Iran. Cardiol Res Pract. 2012;2012:973974.

15. Vincelj J, Bitar L, Jendricko T, Udovicic M, Petrovecki M. Healthrelated quality of life five years after coronary artery bypass graft surgery. Int J Cardiol. 2015;182:68-9.

16. Borkon AM, Muehlebach GF, House J, Marso SP, Spertus JA. A comparison of the recovery of health status after percutaneous coronary intervention and coronary artery bypass. Ann Thorac Surg. 2002;74(5):1526-30; discussion 30.

17. Moattari M, Adib F, Kojuri J, Tabatabaee SH. Angina selfmanagement plan and quality of life, anxiety and depression in post coronary angioplasty patients. Iran Red Crescent Med J. 2014;16(11):e16981.

18. Taheri Kharame Z, Heravi Karimooi M, Rejeh N, Montazeri A, Hajizadeh E. Quality of life in angina pectoris patients: Assessing with the Seattle Angina Questionnaire (SAQ). Journal of Critical Care Nursing. 2014;7(2):124-31.

19. Zhang Z, Mahoney EM, Stables RH, Booth J, Nugara F, Spertus $\mathrm{JA}$, et al. Disease-specific health status after stent-assisted percutaneous coronary intervention and coronary artery bypass surgery: one-year results from the Stent or Surgery trial. Circulation. 2003;108(14):1694-700.

20. Stafford L, Berk M, Jackson HJ. Are illness perceptions about coronary artery disease predictive of depression and quality of life outcomes? Journal of psychosomatic research. 2009;66(3):211-20.

21. Najafi M, Sheikhvatan M, Montazeri A, Sheikhfathollahi M. Reliability of World Health Organization's Quality of Life-BREF versus Short Form 36 Health Survey questionnaires for assessment of quality of life in patients with coronary artery disease. $J$ Cardiovasc Med (Hagerstown). 2009;10(4):316-21.

22. Montazeri A, Goshtasebi A, Vahdaninia M, Gandek B. The Short Form Health Survey (SF-36): translation and validation study of the Iranian version. Qual Life Res. 2005;14(3):875-82.

23. Spertus JA, Winder JA, Dewhurst TA, Deyo RA, Prodzinski J, McDonell M, et al. Development and evaluation of the Seattle Angina Questionnaire: a new functional status measure for coronary artery disease. J Am Coll Cardiol. 1995;25(2):333-41.

24. Ravand M, Attarbashi Moghadam B, Meraci M, Ravand M, Rezaeian Z. The Reliability and Validity of Persian Version of the Seattle Angina Questionnaire in Patients with Myocardial Infarction. Journal of Research Rehabilitation Sciences. 2013;9(5):805-17.

25. De Smedt D, Clays E, Annemans L, Boudrez H, De Sutter J, Doyle $\mathrm{F}$, et al. The association between self-reported lifestyle changes and health-related quality of life in coronary patients: the EUROASPIRE III survey. Eur J Prev Cardiol. 2014;21(7):796-805.

26. Norekval TM, Wahl AK, Fridlund B, Nordrehaug JE, WentzelLarsen T, Hanestad BR. Quality of life in female myocardial infarction survivors: a comparative study with a randomly selected general female population cohort. Health Qual Life Outcomes. 2007;5:58. 